\title{
IMPLEMENTASI DESAIN 'NAME BOARD’ DESA WISATA JAMBU GONDANGMANIS KABUPATEN JOMBANG
}

\author{
Nurin Fitriana \\ Universitas Wisnuwardhana Malang: Jalan Danau Sentani Raya No.99Kota Malang \\ e-mail: nurinfitriana86@gmail.com
}

\begin{abstract}
Abstrak
Lokasi kebun penghasil jambu gondangmanis terbesar di Kecamatan Bandarkedung Mulyo Kabupaten Jombang masih tergolong susah untuk ditemukan oleh masyarakat luar Jombang. Padahaldidaerah ini memiliki komoditi hasil pertanian utama unggulan daerah yaitu berupa Jambu Gondangmanis. Jambu Gondangmanis telah dikenal oleh masyarakat Jombang dan sekitarnya sejak tahunan yang lalu namun perkembangannya hingga menjadi sentra produksi di desa Gondangmanis belum tampak. Kurangnya promosi lokasi kebun jambu menjadifaktor kurang dikenalnya jambu gondangmanis. Dengan demikian perlu dipikirkan bagaimana langkah-langkah mempromosikan pusat perkebunan jambu sehingga masyarakat yang melewati daerah tersebut dapat lagsung mengetahui wilayah wisata jambu gondangmanis. Kegiatan yang akan dilakukan ini bertujuan untuk 1) memberikan rancangan desain name board berupa papan nama; 2) pembuatan name boardyang menarik untuk mempromosikan daerah wisata jambu gondang manis dari sticker high resolution plat aluminium. Hal tersebut bertujuan untuk mempermudah pengunjung mengetahui letak kebun desa wisata dan mempromosikan komoditi jambu gondang manis pada masyarakat lebih luas. Kegiatan pengabdian ini memiliki target luaran berupa produk desain papan nama dan papan nama sticker high resolution plat aluminium dengan besi holow yang terpasang di desa Bandarkedung Mulyo Jombang. Sehingga melalui kegiatan pengabdian ini dapat membantu penyebarluasan promosi desa wisata di kalangan masyarakat dan pengunjung dari daerah luar wilayah Jombang.
\end{abstract}

Kata kunci :desain, wisata jambu,name board

\section{PENDAHULUAN}

Pembuatan papan nama/ name board yang menarik dan bersifat dapat mempromosikan jambu gondangmanis sangat diperlukan oleh desa Bandarkedung Mulyo Jombang. Hasil Perkebunan buah jambu di wilayah inimelimpah. Akan tetapi kurangnya upaya promosi dari masyarakat menjadikan susahnyapenjualan jambu gondangmanis ke masyarakat luar jombang. Ketidaktahuan letak lokasi desaini menjadi salah tau kendala terbesar bagi masyarakat luar daerah jombang untuk menjadi konsumen karenamereka harus banyak bertanya kesana kemari tentang lokasi desa ini. Hal ini merupakan faktor terhambatnya kegiatan perkembangan perekonomian masyarakat petani jambu gondangmanis. Dengan kondisi tersebut, maka harus di rencanakan pembuatan signage yang benar. Dalam penyampaian pesan juga dibutuhkan media yang berupa papan nama. Papan nama ini biasanya tergantung lokasi yang strategis [1]. 
Seharusnya papan reklamememiliki konsep penataan secarahirarkis dan terorganisir di setiappenempatannya. Penataan papanreklame secara hirarkis dan terorganisirtersebut dapat memberikan keuntunganganda bagi pemerintahan, yaitupeningkatan pendapatan daerah yangdiperoleh dari media luar ruang, dandapat mempercantik kota serta dapatmemberikan akses informasi kepadamasyarakat, khususnya mengenaiinformasi yang terpampang pada papanreklame tersebut[2].

Pemasangan papan reklameselalu memilih tempat yang strategisbaik di jalan maupun di bangunan. Inidilakukan oleh berbagai pihak dengantujuan mempromosikan sesuatu danmenarik perhatian orang sebanyakmungkin serta untuk meningkatkankejelasan detail dari pesan-pesan yangdisampaikan.Selain itu penentuan lokasipapan reklame menyangkut efektifitasmedia ruang luar sangat mempengaruhiefek penerimaan konsumen [3]. Terdiri dari: arah perjalanan, jenis produk,jangkauan, kecepatan arus lalu lintas,persepsi terhadap lokasi, dan keserasiandengan bangunan sekitar.Karena itu suatu papan reklameyang ideal adalah :

1. Mampu merefleksikan karakter visual kawasan.

2. Mampu menjamin kemampuan pandangan / memiliki sudut pandang untuk dapat dilihat secara jelas.

3. Bentuk yang ada sesuai dengan arsitektur bangunan di mana signage ditempatkan.

4. Merupakan elemen yang menyatu dengan bangunan bukan elemen tambahan.

5. Mampu menyatukan komunikasi langsung atau tidak langsung.

Ada Beberapa keunggulan dankelemahan iklan luar ruang menurutDeddy Mulyana dkk [4]. Keunggulan papan reklamesebagai iklan luar ruang yaitu :

1. Jangkauannya luas, pesan dapat disampaikan kesemua segmen masyarakat.

2. Durasi penayangan lebih lama darimedia lainnya, dapat mencapaihitungan bulanan atau tahunan.

3. Tidak ada biaya langsung yangditanggung oleh konsumen.

4. Mempunyai potensi untuk menarikperhatian melalui ukuran dan warnamedia yang mencolok.

5. Adanya efek pengulangan pesanyang berkali-kali setiap melihatnya.

Penunjuk arah atau papan nama sebagai penanda desa pun belum terpasang di desa Bandarkedung Mulyokabupaten Jombang, padahal adanya identitas tersebut dapat memudahkan wisatawan domistik wilayah luar Jombang untuk mengetahui pusat keberadaan kebun jambu gondangmanis.

Adapun pelaksanaan untuk pengerjaan desain name board lokasi wisata jambu gondangmanis Jombang dilaksanakan dua tahap.Tahap 1: Membuat desain name board, Tahap 2: Membuat name board dari sticker high resolutiondengan plat aluminium. Program Pengabdian Masyarakat ini terselenggara berkat kerjasama antara pihak Universitas Wisnuwardhana Malang dengan Desa Bandarkedung Mulyo Kabupaten Jombang.

Jambu Gondangmanis khas wilayah Jombang adalah salah satu varietas jambu bol yang telah menjadi varietas unggul nasional yang mulai dikenal dan pangsa pasarnya tinggi di swalayan. Jambu bol Gondangmanisini telah dikenal oleh masyarakat Jombang dan sekitarnya sejak ratusan tahun yang lalu namun perkembangan hingga menjadi sentra produksi di desa Gondang Manis, kecamatan Bandarkedungmulyo sekitar 30 tahun yang lalu.

Jambu bol (Syzygium malaccense) termasuk famili Myrtaceae yang berasal dari Asia Tenggara yang keberadaannya terbatas di Jawa, Sumatra dan Semenanjung Malaysia. Beberapa bagian dari tanaman kelompok Syzygium ini digunakan dalam obat-obatan tradisional karena memiliki aktivitas antiobitik. Khususnya kulit batang, daun dan akar jambu bol sering digunakan untuk menyembuhkan penyakit.

Jambu bol ini merupakan produk unggulan Jombang karena memiliki potensi antara lain nilai ekonomis cukup tinggi serta warna buah yang sangat menarik (ungu kehitaman jika buah telah tua dan merah muda keunguan jika buah masih muda), bentuk dan ukuran buah sedang, rasa buah segar, warna daging buah putih bersih dan tekstur dalam buah lunak seperti diselimuti kapas sertaa 
aroma buah yang harum. Konsumen sangat menyukai rasa segar sedikit asam, daging buah tebal dan kenyal serta penampilan jambu bol yang khas.Saat ini tanaman jambu bol yang ada masih ditanam dan dikembangkan di pekarangan.

Jumlah tanaman yang ada di desa Gondangmanis , kecamatan Bandarkedungmulyo kabupaten Jombang lebih dari 600 pohon dengan kisaran umur 10 hingga 30 tahun. Nampaknya di Jawa Timur pertanaman jambu bol yang ada dalam satu kawasan atau dalam satu desa dan telah diusahakan hingga peluang pasar sampai pasar swalayan hanya jambu bol Gondangmanis [5].
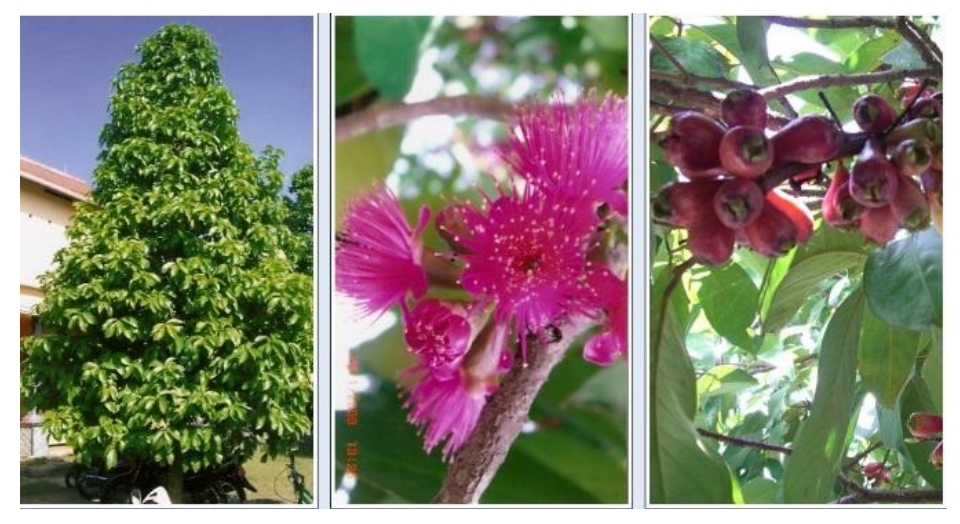

Gambar 1. Pohon, bunga dan buah jambu Gondangmanis Khas Jombang
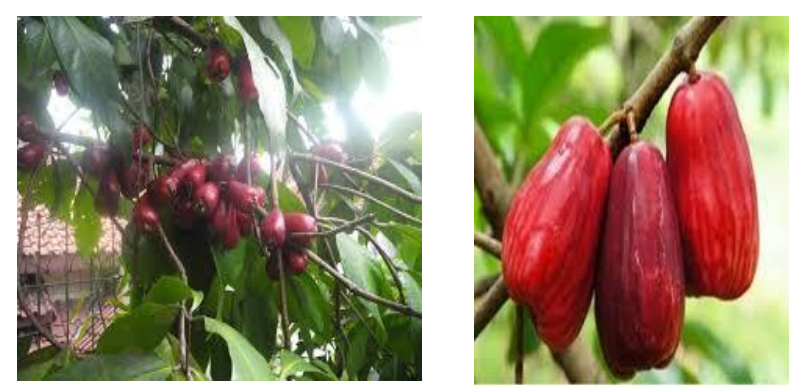

Gambar 2. Buah Jambu Gondangmanis

Berdasarkan hasil wawancara dengan kepala desa Bapak Suharno ada beberapa data yang bisa diperoleh yaitu, pada umumnya tanaman jambu bol tumbuh dan berproduksi pada dataran rendah hingga ketinggian $1200 \mathrm{~m}$ dari permukaan laut dengan lingkungan yang baik dan ternaungi dan cenderung tumbuh di daerah tropis basah. Tanaman jambu bol Gondangmanis mulai berbunga sekitar bulan April- Mei dan panen pada bulan Agustus-September. Persentase bunga menjadi buah (fruit set) sekitar $80 \%$ per tandan. Umur simpan buah sekitar 3 hari dari panen pada suhu kamar. Daya tahan simpan ini merupakan permasalahan utama karena kulit buah jambu bol sangat tipis sehingga mudah lecet dan busuk.

Potensi Ekonomis

Penilaiankeunggulan jambu bol khas Jombang Gondangmanis dapat dilihat dari potensi ekonomis. Pemilik tanaman jambu bol di desa Gondangmanis kecamatan Bandarkedung Mulyo, Jombang selalu mengatakan bahwa tanaman jambu bol yang dimiliki sangat membantu di dalam menunjang kebutuhan hidup mereka. Hal ini karena harga jambu bol di tingkat petani berkisar antara Rp 7.000,- hingga Rp 8.000,-. Pohon jambu bol yang baru pertama kali berbuah asal dari biji (umur 4-5 tahun) dapat menghasilkan buah sebanyak 40-50 kg, pada umur 20-25 tahun menghasilkan $200-350 \mathrm{~kg} /$ pohon. 


\section{METODE KEGIATAN}

Kegiatan ini menggunakan metodologi desain sebagai acuan pelaksanaannya dengan judul Pembuatanname board. Pelaksanaan desain didahului dengan mengadakan survey ke lokasi tempat dimana meletakkan name board atau papan nama tersebut akan direalisasikan karena lokasi yang tepat harus berada di posisi yang strategis, yaitu harus mudah dilihat dari berbagai arah, tidak terhalang oleh apapun baik itu pepohonan, dinding atau apapun yang dapat menghalangi informasi dari papan nama yang akan dibuat. Tahapan kegiatan sebgai berikut:

1) Memberikan rancangan desain papan nama (name board) dari bahan sticker high resolution plat aluminium dengan pipa hollow;

2) Membuatkan papan nama (name board) desa wisata jambu gondang manis yang menarik bagi wisatawan domistik untuk mempromosikan wilayah desa wisata jambu gondang manis.

Desain papan nama desa wisaya jambu gondangmanis ini didasarkan pada aspirasimasyarakat yang ditampung dan diolah sebagai acuan dalam proses perancangan. Dengan melihat aspirasi masyarakat tersebut kebutuhan masyarakat akan suatu teknologi dapat terpenuhi dan tidak berseberangan dengan keinginan masyarakat, sehingga masyarakat merasa memiliki dan berusaha memeliharanya.

\section{HASIL DAN PEMBAHASAN}

\subsection{Program Perencanaan Desain Papan Nama (Name Board)}

Kesadaran akan butuhnya name board sebagai media informasi dan promosi mengenai keberadaan petani jambu Gondangmanis Jombang. Lebih dikenalnya letak Desa Bandangkedung Mulyo sebagai penghasil terbesar jambu gondangmanis adalah keinginan dari masyarakat Bangdarkedung Mulyo.

Alur pengabdian kepada masyarakat yang dilakukan ini dapat dilihat dari diagram berikut:

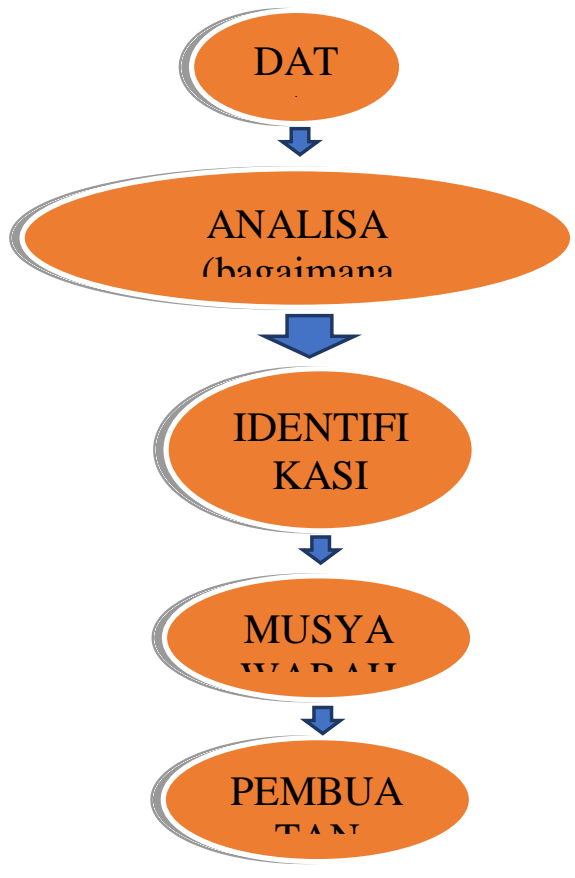

Gambar3. Digram alur pengabdian 


\subsection{Sticker High Resolution Plat Aluminium}

Bahan yang digunakan untuk tulisan atau gambar dalam pembuatan papan namai ini adalah sticker berlaminasi yang dapat diaplikasikan di luar ruang, tahan terhadap air dan sinar matahari. Jika dilihat dari bahan striker makayang termasuk sticer outdor adalah bahan vinyl, yaitu bahan semacam plastic tipis yang tidak bisa sobek seperti kertas, selain itu juga tidak bisa rusak jika kena air hujan. Stiker outdoor dicetak menggunakan tintaanti air dan UV, tinta jenis ini biasanya termasuk jenis tinta berbasis solvent atau minyak contohnya tinta eco-solvent atau solvent yang paling banyak dipakai dalam dunia digital printing.

\section{Tujuan Kegiatan}

Melalui kegiatan ini kami mengajak seluruh masyarakat untuk turut serta membantu kami baik secara moril materil dan bantuan lainnya sebagai wujud pengabdian masyarakat khususnya Pihak Universitas Wisnuwardhana Malang. Maksud dan tujuan kegiatan ini adalah melaksanakan P2M dengan memberikan kontribusi berupa Desain Name Board lokasi wisata jambu gondang manis Jombang, adalah:

1. Terwujudnya sarana informasi berupa name boardyang mudah dilihat.

2. Tumbuhnya perekonomian hasil penjualan jambu Gondangmanis karena semakin dikenal masyarakat luas.

3. Terwujudnya kemudahan masyarakat luas untuk mengunjungi lokasi wisata jambu Gondangmanis Jombang.

\section{Tempat Pelaksanaan}

Kegiatan ini direncanakan akan direalisasikan di Desa Bandarkedung Mulyo Kabupaten Jombang dengan lokasi pemasangan papan nama di gapura jalan raya tepat di depan jalan masuk menuju lokasi petani penghasil Jambu Gondangmanis Desa Bandarkedung Mulyo.

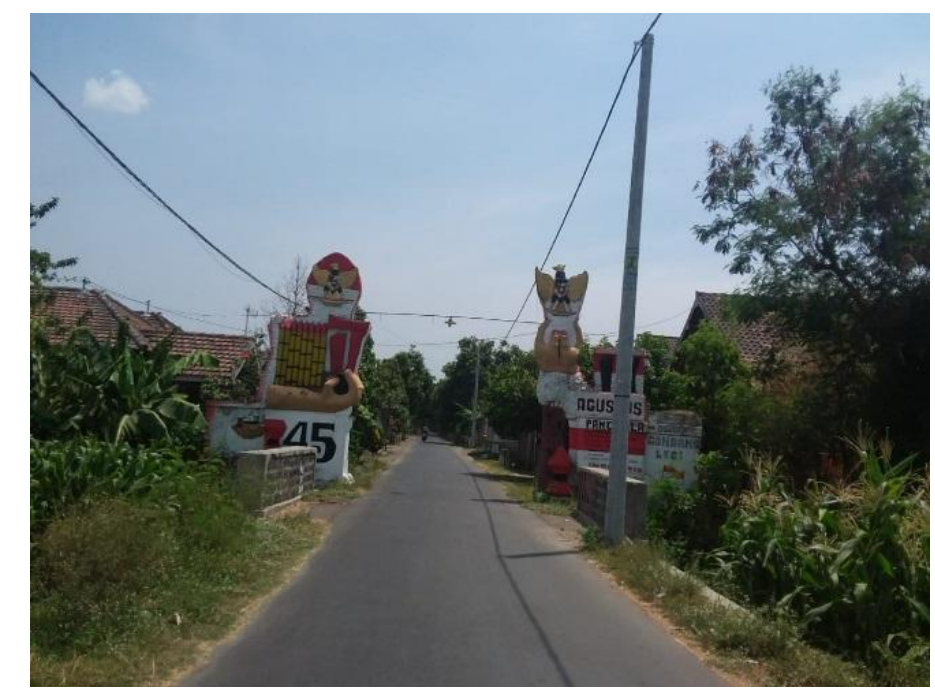

Gambar 4. Lokasi gapura peletakan Name Board

Desain Name Board

Pembuatan desain name board (papan nama) dilakukan tanggal 10 Oktober hingga 15 Oktober 2018. Diperoleh hasil sebagai berikut: 
1. Desain sticker high resolution + laminasi yang dipasang pada plat aluminium

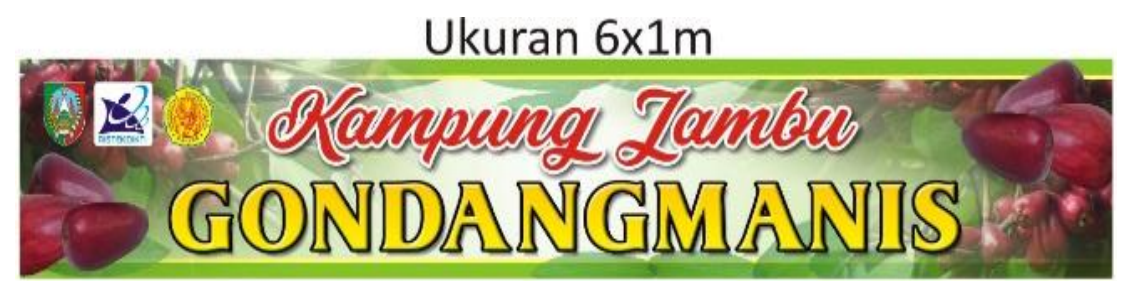

Gambar 5. Desain name board

Plat aluminium adalah lembaran plat atau pelat logam yang ringan dan kuat. Plat aluminium memiliki sifat anti karat, tidak mudah terbakar dan tahan terhadap segala jenis cuaca. Plat jenis ini sendiri mudah dibentuk, sehingg banyak digunakan dalam bidang industri seperti dalam kebutuhan advertising.

Terdapat dua jenis aluminium diantaranya, aluminium tuang yang dapat menghantar listrik dan aluminium tempa yang memiliki kekuatan tarik. Bahan aluminium juga meruapakan konduktor listrik yang dapat menghantarkan listrik dengan baik, sehingga biasanya untuk plat aluminium yang digunakan sebagai bahan baku dalam industri advertising atau pembuatan reklame akan dilakukan proses anodizing yaitu proses membuat aluminium tidak menghantarkan listrik yang kemudian dipanaskan agar tahan terhadap panas udara atau panas air.

2. Desain rangka besi pipa holow dengan plat aluminium

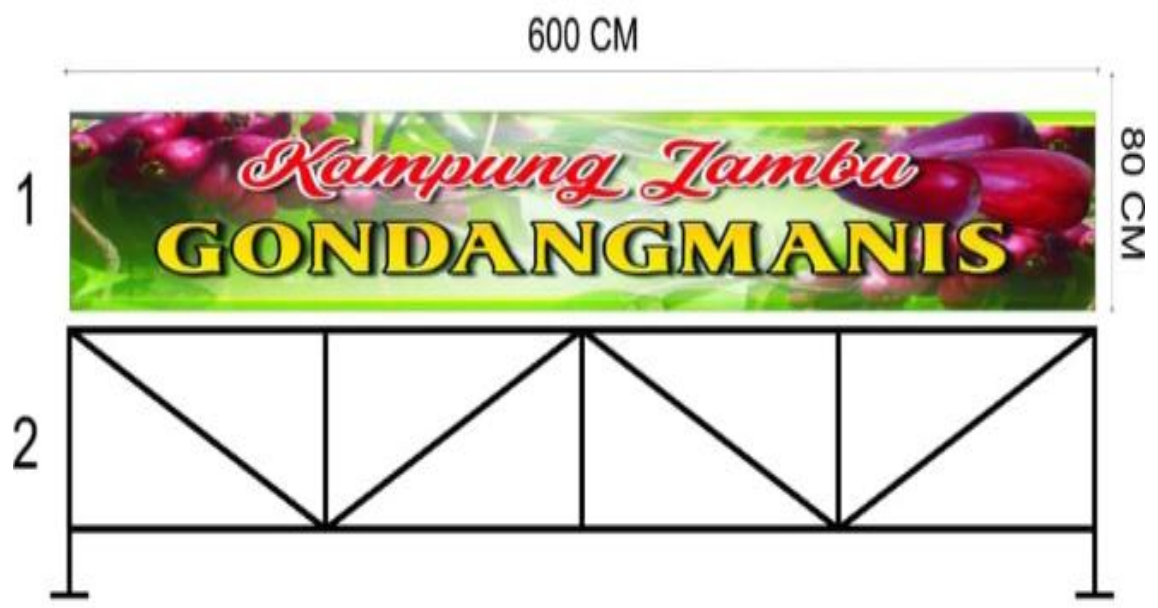

Gambar6. Rangka Besi

Saat ini hampir seluruh konstruksi bangunan menggunakan besi hollow. Bukan hanya mengutamakan kualitasnya yang kokoh, tapi saat ini konstruksi juga memperhatikan unsur estetika sebuah material bangunannya. Besi hollow cukup popular karena memiliki banyak kegunaan, baik untuk kanopi, pintu pagar, teralis modern, sampai pemasangan plafon gypsum dan plafon GRC board. Besi hollow umumnya terbuat dari besi galvanis, stainless, atau besi baja.

Besi hollow jenis gypsum merupakan material bahan bangunan yang banyak diminati dan kokoh dan tahan lama. Hollow gipsum banyak digunakan untuk pembuatan rangka papan nama. Alasan pemilihan besi hollow jenis ini untuk papan nama adalah karena ringan, kokoh, serta kualitasnya jauh lebih bagus dibandingkan dengan jenis besi yang lain. 
3. Desain rangka dengan Lampu sorot LED

\section{$550 \mathrm{~cm}$}

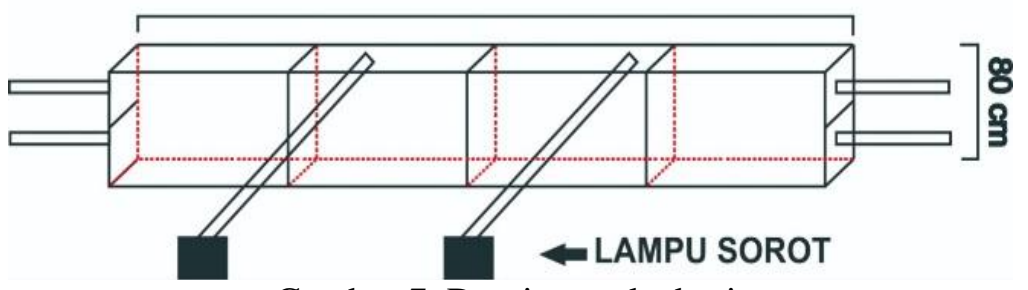

Gambar 7. Desain rangka besi

Lampu LED Modul Backlight Papan Reklame adalah Lampu LED Modul untuk kebutuhan Channel Lettering (advertising), Backdrop Ruangan (interior), Drop Ceiling (interior), dll seperti aplikasi pengunaan Backlight Papan Reklame untuk pencahayaan dari dalam yang biasa digunakan untuk advertising signs, cover bahan digital printing, vinnyl ataupun Billboardacrylic, neon board, channel-letter, huruf timbul, celling lamp, dll

Penggunaan Lampu LED pada papan nama, agar saat malam hari tetap terlihat terang dan menunjukkan identitas desa Bandarkedung mulyo sebagai desa wisata jambu gondangmanis.

Bahan Yang Digunakan

Pipa Holow UK 3X3X1.6

Pipa Gas $3 / 4$ X 1.8

Plat Aluminium 0.8

Stiker High Resolution + Laminasi

Rangka Besi UK 550 x $80 \mathrm{~cm}$

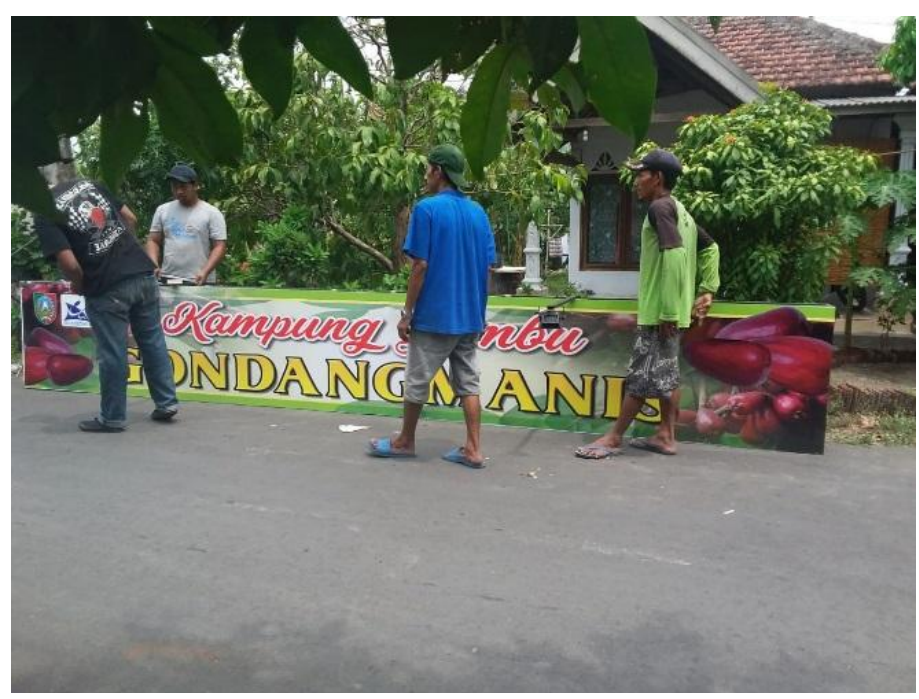

Gambar 8. Name Board yang sudah jadi dan dipasang

Warga desa Bandarkedung Mulyo bersama-sama berkoordinasi pemasangan name board/papan nama yang akan dipasang di gapura jalan masuk desa wisata jambu gondangmanis. 


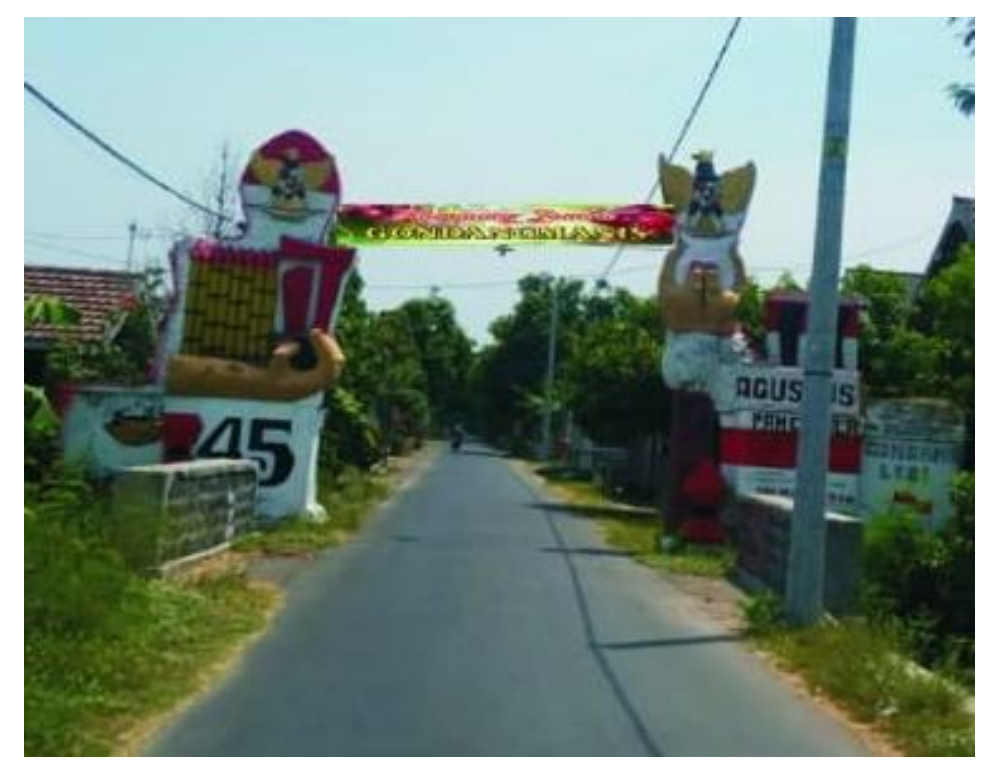

Gambar 9. Hasil Pemasangan Name Board

Jadwal Pembuatan

Pembuatan name board atau papan nama, dilaksanakan yang dimulai pada 16 oktober sampai 23 Oktober 2018. Untuk pemasangan name board dilaksanakan pada tanggal 25 Oktober 2018 bersama-sama warga setempat dan perangkat desa.

\section{KESIMPULAN}

Desa Bandarkedung Mulyo Kabupaten Jombang merupakan kawasan yang berpotensi dalam penghasil jambu Gondangmanis terbesar di kabupaten Jombang. Wilayah inilayak untuk dijadikan sebagai salah satu tempatwisata jambu gondangmanis. Pengembangan desain name board untuk Kawasan ini bertujuan untuk mempromosikan kepada masyarakat luas khususnya dari luar wilayah Jombang agar daerah ini lebih dikenal oleh masyarakat. Hal tersebut diharapkan dapatmeningkatkan perekononiam masyarakat petani jambu di wilayah Jombang. Daya dukung Kawasan wisata jambu ini relatif cukup memadai untuktumbuh dan berkembang sebagai kampung wisatayang unik.

Hal-hal penting yang disarankan dandiusulkan

untuk mendukung terwujudnya pengembangankampung wisata jambu ini adalah : (1).Perluadanya bantuan pemerintah daerah untukmendukung, mengawasi dan konsistensimembangun kawasan wisaa jambu gondangmanis dari pemerintah; (2) perlu bantuan daripenduduk/masyarakat setempat untuk mendukung,memelihara dan menjaga kualitas lingkunganserta mempertahankan kebun penghasil jambu yang ada di kampung wisata ini.

\section{SARAN}

Perlu dibuatkan papan petunjuk arah dari titik masuk wilayah Kabupaten Jombang yang menunjukkan lokasi desa wisata Jambu Gondangmanis. 


\section{DAFTAR PUSTAKA}

[1] Sahayu, Wening. 2010. Bentuk dan Fungsi Komunikasi Tulis Pada Papan Nama di Lingkungan Kampus. Jurnal Penelitian Humaniora Vol.8 No. 1 April, https://journal.uny.ac.id/index.php/humaniora/article/view/5765/4975 diakses tanggal 10 Oktober 2018.

[2] Wartina, Ida. 2015. Kajian Terhadap Penempatan Papan Reklame Untuk Menjaga Kualitas Visual Kawasan Komersial dan Kawasan Konservasi. http://ejurnal.bunghatta.ac.id/index.php?journal=JPSC2\&page=article\&op=viewFile\&path[]=6 896\&path[]=5827, diakses tanggal 10 Oktober 2018.

[3] Fuad, Ahmad. 2015. Pembuatan Papan Nama Dan Petunjuk Arah Panti Asuhan Insan Madani Di Kampung Masjid Dusun Lemah Duhur Gunung Bunder 1 Bogor. Jurnal Abdimas Volume 1 Nomor 2 Bulan Maret2015. http://digilib.esaunggul.ac.id/public/UEU-Journal-7283PEMBUATAN\%20PAPAN\%20NAMA\%20DAN\%20PETUNJUK\%20ARAH_Fuad.pdf, diakses tanggal 12 Oktober 2018.

[4] Ulrich, T. K and Eppinger D.S. 2001. Perancangan dan Pengembangan Produk. Jakarta: Salemba Teknika.

[5] Dinas Pertanian Kabupaten Jombang. 2012. Jambu ol Varietas Jambu Gondangmanis. http://pertanian.jombangkab.go.id/component/content/article/45-profil-disperta/258-jambubol-varietas-gondang-manis, diakses tanggal 9 Oktober 2018. 